\title{
Immunohistochemical expression of Cyclin D1 among Sudanese patients diagnosed with benign and malignant prostatic lesions
}

\author{
Eiman Siddig Ahmed' ${ }^{1}$ Lubna S. Elnour ${ }^{2}$, Rowa Hassan ${ }^{1}$, Emmanuel E. Siddig 1,2,3,4, Mintu Elsa Chacko5, \\ Eman T. Ali ${ }^{2,6}$, Mona A. Mohamed ${ }^{7}$, Abdalla Munir ${ }^{8}$, Mohamed S. Muneer ${ }^{9,10,11}$, Nouh S. Mohamed ${ }^{7,12,13^{*}}$ (D) \\ and Ali M. M. Edris ${ }^{2,14}$
}

\begin{abstract}
Objectives: Prostate cancer (PC) is common cancer worldwide. Several markers have been developed to differentiate between benign prostatic hyperplasia (BPH) from PC. A descriptive retrospective hospital-based study aimed at determining the expression of Cyclin D1 in BPH and PC. The study took place at different histopathology laboratories in Khartoum state, Sudan, from December 2016 to January 2019. Formalin-fixed paraffin-embedded blocks were sectioned and fixed in 3-aminopropyltriethoxysilane coated slides incubated into primary antibody for Cyclin D1. The assessment of immunoreactivity of Cyclin D1 of each section was done using the Gleason scoring system.

Results: A total of 153 males' prostate sections included in this study, of them, 120 (78.4\%) were PC, and 33 (21.6\%) were BPH. Their age ranged from 45 to 88 years, mean age was $66.19 \pm 8.599 .142$ (92.8\%) did not have a family history of PC, while 11 (7.2\%) patients reported having a family history. The Gleason scoring showed a total of 81 (52.9\%) patients with high-grade and 39 (25.5\%) with low-grade. 118 (97.5\%) patients had PC showed positive results for Cyclin D1, while BPH was 3 (2.5\%). P value $<0.001$. Cyclin D1 staining was associated with high-grade Gleason score and perineural invasion, $P$ value 0.001.
\end{abstract}

Keywords: Prostate cancer, Immunohistochemical expression, Prognostic markers, Cyclin D1

\section{Introduction}

Prostate cancer (PC) is considered as the third most common type of cancer worldwide and the second most cancer among males with estimated 1,276,106 PC cases in 2018 with 358,989 deaths worldwide [1]. Consequently, several markers have been developed over the last years to differentiate between benign prostatic hyperplasia $(\mathrm{BPH})$ from $\mathrm{PC}[2,3]$.

Cyclin D1 is a member of proteins that belong to D-type Cyclin family; those are involved in the regulation

\footnotetext{
*Correspondence: nouh_saad@outlook.com

${ }^{13}$ Molecular Biology Department, Alfarrabi College for sciences and Technology, Khartoum, Sudan

Full list of author information is available at the end of the article
}

of cell cycles by mediating the phosphorylation and inactivation of the retinoblastoma protein, allowing the cells to progress from G1 phase to S phase [4]. High expression of Cyclin D1 was noticed among different types of malignancy, including Breast cancer [4], colon cancer [5], and lung cancer $[6,7]$. There are many studies that investigated the role of Cyclin D1 expression in PC; Pereira et al., correlated the expression of Cyclin D1 to be associated with perineural invasions and with the aggressive form of the disease [8].

In Sudan, PC is one of the cancers that always being lately presented [9], since most of the patients are suffering from stigmatization and poverty, this might cause the inability of the patient to early screen for the disease as well as continue to follow up to ensure adequate

(c) The Author(s) 2020. This article is licensed under a Creative Commons Attribution 4.0 International License, which permits use, sharing, adaptation, distribution and reproduction in any medium or format, as long as you give appropriate credit to the original author(s) and the source, provide a link to the Creative Commons licence, and indicate if changes were made. The images or other third party material in this article are included in the article's Creative Commons licence, unless indicated otherwise in a credit line to the material. If material is not included in the article's Creative Commons licence and your intended use is not permitted by statutory regulation or exceeds the permitted use, you will need to obtain permission directly from the copyright holder. To view a copy of this licence, visit http://creativeco mmons.org/licenses/by/4.0/. The Creative Commons Public Domain Dedication waiver (http://creativecommons.org/publicdomain/ zero/1.0/) applies to the data made available in this article, unless otherwise stated in a credit line to the data. 
treatment and avoid depraved prognosis to increase life expectancy [10]. During 2009-2010, a total of 6771 new cancer cases were registered, of them, 387 (\%) were PC cases [10]. Also in 2009-2013, PC was one of the top 5 prevalent cancers in Sudan, about 2000 PC cases were reported in that period with a $10 \%$ mortality rate $[10$, 11]. In Sudan, scarce data about the expression level of Cyclin D1 among Sudanese PC patients, as this is attributed to the lack of expression studies [9]. Therefore, not only investigation towards appropriate marker can be used to predict the prognosis of PC among males in Sudan, but also will lead for a better patients' management and upcoming with efficient follow up strategies. Hence, in this study, we aimed to investigate the Cyclin D1 expression in patients with $\mathrm{BPH}$ and PC and to correlate the expression with the clinical characteristics of the patients, and to emphasize the use of Cyclin D1 as a diagnostic and prognostic marker for PC in Sudan.

\section{Main text}

\section{Materials and methods}

A descriptive retrospective hospital-based study conducted at two histopathology laboratories; the Military Hospital and Soba teaching hospital, in Khartoum stateSudan, from December 2016 to January 2019. The study samples included 153 formalin fixed paraffin embedded blocks from patients diagnosed with BPH $(\mathrm{n}=33)$ and $\mathrm{PC}(\mathrm{n}=120)$.

\section{Preparation of slides toward immunohistochemistry}

From each paraffin embedded block, two sections were cut. One section was stained using hematoxylin and eosin technique $(\mathrm{H} \& \mathrm{E})$. The second section was mounted onto 3-aminopropyltriethoxysilane coated slides (LabScientific, NJ-USA). Antigen retrieval was performed by treating the section in citrate buffer incubated in a water bath at $96^{\circ} \mathrm{C}$ for $10 \mathrm{~min}$. Then, slides were rinsed in distilled water and treated with $3 \%$ hydrogen peroxide in a methyl alcohol solution for $15 \mathrm{~min}$. After that, slides were rinsed in a washing buffer for $5 \mathrm{~min}$. The sections were then incubated in the primary antibody (rabbit monoclonal antibody to Cyclin D1, clone EPR2241, Biogenex, CA-USA) at room temperature for $2 \mathrm{~h}$. After that, the staining was performed according to manufacturer protocol. For the positive control, a section from a known colon cancer tissue block was used. Whereas, for the negative control, another tissue section was used without applying the primary antibody.

\section{Assessment of immunoreactivity of Cyclin D1}

The assessment of immunoreactivity of Cyclin D1 was done using the Gleason scoring system [12]; $1+$ if $10 \%$ of the cells expressed the marker, $2+$ if $>10-25 \%$ of the cells are expressing the marker, $3+$ if $>25-75 \%$ of the cells showed expression of the marker and $4+$ if more than $75 \%$ of the cells expressed the marker. $1+$ and $2+$ were considered as low-grade, while $3+$ and $4+$ were considered as high-grade expression. Gleason scoring for grade 1 and 2 when simple round glands, close-packed or loosely packed in vague in rounded masses with well- or loosely defined edges, and grade 3; glands appear with varying small sizes irregular shape and irregular spacing with infiltrating edges. Whereas, grade 4; when glands sizes were small, medium, or large and fused into cords or ragged, with infiltrating masses.

\section{Statistical analysis}

Data were analyzed using the Statistical Package for Social Sciences (SPSS) version 16. Pearson correlation with 95\% confidence interval was used to test the association of Cyclin D1 expression with age. Chi Square test was done to test the significance of age with diagnosis and Cyclin D1 grade with the diagnosis categories. ANOVA test were done to test the association of age with family history, perineural invasion and angiolymphatic invasion. $\mathrm{P}$ value $<0.05$ was considered a statistically significant.

\section{Results \\ Study characteristics}

A total of 153 male participated in this study, of them, 120 (78.4\%) were PC patients, and 33 (21.6\%) were BPH. Age of the study participants ranged from 45 to 88 years, with a mean age of $66.19 \pm 8.599$. Among the 153 patients, 142 (92.8\%) did not have a family history of PC, while $11(7.2 \%)$ patients were reported to have a family history of PC.

\section{Analysis results based on participant's age}

No association for age with Gleason score, family history, perineural invasion, angiolymphatic invasion and diagnosis (P values; 0.957, 0.110, 0.187, 0.466, 0.933 and 0.853 respectively). However, Gleason scoring were found to be positively correlated with patients age $(\mathrm{P}$ value $=0.711$, Person's $r=0.030$ ).

\section{Analysis based on age grouping}

Participants were grouped into 4 groups according to their age group; a group of less than 60 years consisted of $29(19.0 \%)$ patients, $60-69$ years age group consisted of $74(48.4 \%)$ patients, $70-79$ years age group composed of $38(24.8 \%)$ and those who are aged 80 years and more than 80 were $12(7.8 \%)$ patients. Of the 120 patients diagnosed with $\mathrm{PC}$, the age range of $60-69$ years was the most frequent age group with a frequency of $48.3 \%$. 
No statistically significant difference was found in the comparison of diagnosis based on the age group, $\mathrm{P}$ value 0.798 . A total of $62(40.5 \%)$ were found to have a perineural invasion among the age group of 60-69 years (45.2\%).

Association between age groups and frequency of perineural invasion was found to be statistically not significant, $\mathrm{P}$ value 0.396 . For the angiolymphatic invasion, a total of $12(7.8 \%)$ were reported. No statistically significant difference for the age group with the frequency of angiolymphatic invasion was found (P value 0.621 ). However, Cyclin D1 was found to be positive among a total of 121 (79.1\%) patients, with the age group 60-69 years.

High-grade Gleason scores were mostly reported among 60-69 years age group; 38 (46.9\%) No statistically significant difference found for Gleason scoring based on age grouping (P value 0.915 ). Based on the family history of the patient with PC, 142 (92.8\%) of study patients did not have any family history of PC, P value 0.361 (Additional file 1).

\section{Analysis based on diagnosis}

Of the total, 121 (79.1\%) patients showed positive results for Cyclin D1 stain, the highest frequency was among patients diagnosed as PC; 118 (97.5\%). While, BPH showed minimal frequency for Cyclin D1 positivity; 3 (2.5\%). Positive Cyclin D1 was highly significant with PC (P value $<0.001$ ) (Fig. 1).

Patient's family history was not associated with having PC or BPH (P value 0.062). Gleason Scoring system showed presence of 39 (25.5\%) patients with low-grade and $81(52.9 \%)$ with high-grade expression.

\section{Analysis based on Cyclin D1 staining results}

Of the 153 Patients, 81 (100\%). While for those with lowgrade Gleason score, 37 (94.9\%) were positively stained. However, 3 (9.1\%) of the BPH were stained positive with Cyclin D1 (Fig. 2). Staining with Cyclin D1 was highly associated with high Gleason Score (P value $<0.001$ ).

Results of Cyclin D1 staining were statistically insignificant among patients with family history of $\mathrm{PC}$, although all participants with a family history; $11(5.2 \%)$ were positively stained with Cyclin D1, P value 0.068 .

All patients having perineural invasion; 62 (40.5\%) of them were positively stained with Cyclin D1. Staining with Cyclin D1 was also highly associated with perineural invasion (P value 0.000). On the other hand, staining with Cyclin D1 did not have a statistically significant difference, for patients who had angiolymphatic invasion, $\mathrm{P}$ value 0.053 (Table 1 ).

The distribution of Cyclin D1 staining results, angiolymphatic invasion, perineural invasion, family history, and Gleason score among BPH and PC patients is described in Additional file 2.

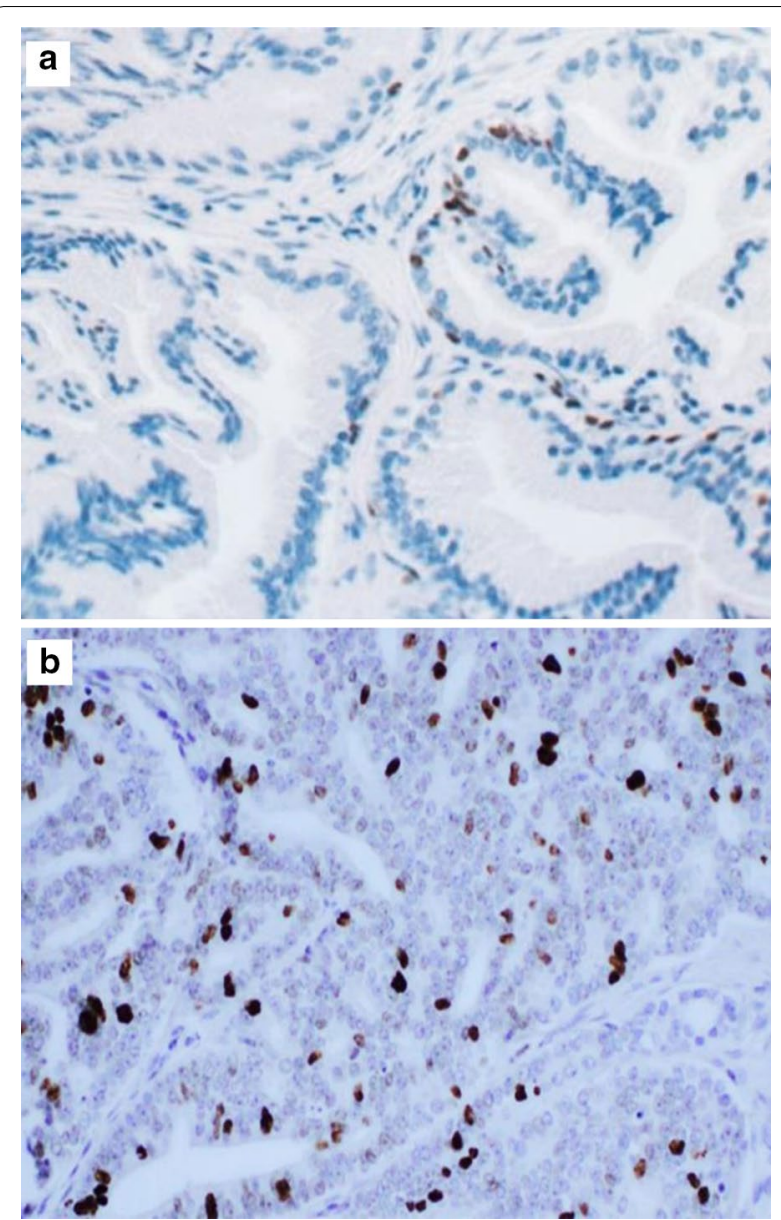

Fig. 1 The correlation of Cyclin D1 immunohistochemistry expression in BPH and PC. a shows the level of expression of cyclin D1 in benign prostatic hyperplasia (BPH), b shows the high expression level of Cyclin D1 in prostate cancer (PC)

\section{Discussion}

PC is considered as the most prominent malignancy encountered in male, especially those above 60 years of age. Prostate malignancy has a characteristic of late presentation and lousy prognosis, especially among Sudanese populations [9]. Although different molecular markers have been used to enable the differentiation between benign and malignant lesions and to predict the prognosis [13-19], varied results were obtained for these markers, in which some were involved in PC development, such as Cyclin D1 which increases its expression in cases of metastasis development [16], and it was correlated with poor prognosis in tumor cells of the breast, pancreas, esophageal carcinoma, and mantle cell lymphoma [20-23]. Cyclin D1 overexpression has reflected the aggressiveness, recurrence, and shortening of patient life expectancy $[24,25]$. In this study, since most of the $\mathrm{BPH}$ 

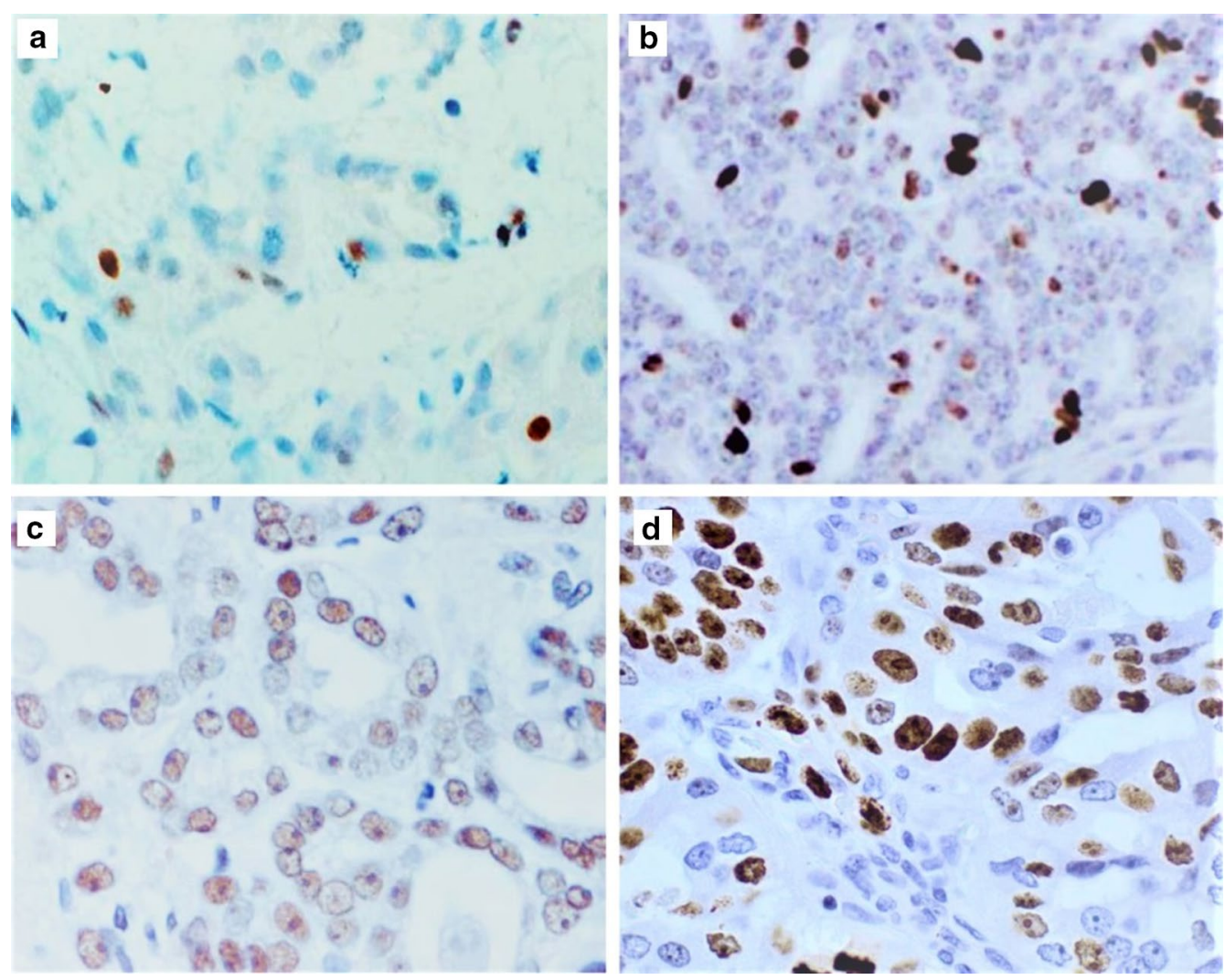

Fig. 2 Photomicroscopy from representative Cyclin D1 immunohistochemistry expression; $\mathbf{a}$ and $\mathbf{b}$ indicates low-grade expression; 10\% to $25 \%$ of the cells were expressing the Cyclin D1. $\mathbf{c}$ and $\mathbf{d}$ indicates high-grade expression, in C: (> 25-75\%) of the cells showed expression of the marker. in $\mathbf{d}$ more than $75 \%$ of the cells expressed the marker

Table 1 Analysis based on Cyclin D1 staining results

\begin{tabular}{|c|c|c|c|c|}
\hline & \multicolumn{2}{|c|}{ Cyclin D1 staining result } & \multirow[t]{2}{*}{ Total } & \multirow[t]{2}{*}{$P$ value } \\
\hline & $\begin{array}{l}\text { Negative } \\
\text { staining }\end{array}$ & $\begin{array}{l}\text { Positive } \\
\text { staining }\end{array}$ & & \\
\hline \multicolumn{5}{|l|}{ Gleason score } \\
\hline Low-grade & $2(5.1 \%)$ & 37 (94.9\%) & 39 (25.5\%) & 0.000 \\
\hline High-grade & $0(0.0 \%)$ & $81(100 \%)$ & 81 (52.9\%) & \\
\hline Normal & $30(90.9 \%)$ & $3(9.1 \%)$ & $33(21.6 \%)$ & \\
\hline \multicolumn{5}{|c|}{ Family history of PC } \\
\hline No & $32(22.5 \%)$ & $110(77.5 \%)$ & $142(92.8 \%)$ & 0.068 \\
\hline Yes & $0(0.0 \%)$ & $11(100 \%)$ & $11(7.2 \%)$ & \\
\hline \multicolumn{5}{|c|}{ Perineural invasion } \\
\hline No & $32(35.2 \%)$ & $59(64.8 \%)$ & 91 (59.5\%) & 0.000 \\
\hline Yes & $0(0.0 \%)$ & $62(100 \%)$ & $62(40.5 \%)$ & \\
\hline \multicolumn{5}{|c|}{ Angiolymphatic invasion } \\
\hline No & $32(22.7 \%)$ & $109(77.3 \%)$ & $141(92.2 \%)$ & 0.053 \\
\hline Yes & $0(0.0 \%)$ & $12(100 \%)$ & $12(7.8 \%)$ & \\
\hline \multicolumn{5}{|l|}{ Diagnosis $^{a}$} \\
\hline $\mathrm{BPH}$ & $30(90.9 \%)$ & $3(9.1 \%)$ & $33(21.6 \%)$ & 0.000 \\
\hline PC & $2(1.7 \%)$ & $118(98.3 \%)$ & $120(78.4 \%)$ & \\
\hline
\end{tabular}

a $B P H$ Benign prostatic hyperplasia, $P C$ Prostate cancer tissues did not show high expression level, although there was a report indicated that the increase in expression of Cyclin D1 is usually rare among PC [26].

In respect to demographical data of patients, the vast majority of PC patients are those between the 5th and 7th decade of their life, and those with a family history of PC. In this study, the reported Cyclin D1 expression was not association with age or patient's family history as reported previously [27]. Even though it is in contrast with the earlier study conducted by Dunsmuir et al., they found an association between age and Cyclin D1 expression [28].

Correspondingly to previous reports [8, 29-32], that stated a significant association especially with highgrade tumors, in this study the reported correlation of Cyclin D1 and Gleason score was statistically significant ( $P$ value $=0,001)$. While in another study expression of Cyclin D1 in BPH was not detected [31], and in another study, although Cyclin D1 is expressed in $\mathrm{BPH}$, rarely Cyclin D1 is overexpressed in cases of PC [26].

In this study, the relation between Gleason Scoring and Cyclin D1 expression were in harmony to previous reports, 
showing a positive relationship between the expression of Cyclin D1 and Gleason score, especially with high-grade tumors $[8,22,29-31]$. While in comparison to other studies, no association was found [29, 33, 34].

In this study, a significant association between the Cyclin D1 expression and the perineural invasion ( $P$ value $<0.001$ ); this result agrees with that of Pereira et al. [8], and He et al. [35]. Their results showed that the overexpression of this marker besides other markers leads to the increase of cells proliferation and transformation. Since Cyclin D1 increases the mobility and invasion of tumor cells, the overexpression of Cyclin D1 is related to the aggressiveness of PC $[35,36]$. Therefore, Cyclin D1 was expressed mostly among patients with perineural invasion. In some studies, Cyclin D1 expression was correlated with poor prognosis in the tumor cells [20-23], and it is overexpression has reflected the aggressiveness of cancer [24, 25]. As well, due to the predictive preoperative usefulness of the Gleason score correlated with Cyclin D1 expression to predict tumor behavior, it became easy to differentiate between malignant and benign disease [37, 38]. However, in some studies, Gleason score did not satisfy that theme $[8,39-41]$.

\section{Conclusion}

The use of Cyclin D1 expression immunohistochemical detection system is a very suitable way for diagnosing PC, especially in low-income settings such as Sudan. Also, Cyclin D1 can also be used as indicative for PC progression and predicting tumor cells invasion to perineural tissues.

\section{Limitations}

- The sample size of this study, although it provided some clues on the expression of Cyclin D1 in Sudanese PC patients, a more extensive study scale with an appropriate follow up of the PC progression would allow these results to be sensible.

- Failure to obtain follow up data of the PC patients reviewed in this study prevent the investigation about the relationship of other PC progressions with Cyclin D1 expression.

\section{Supplementary information}

Supplementary information accompanies this paper at https://doi. org/10.1186/s13104-020-05138-7.

Additional file 1: Table S1. Analysis based on age grouping.

Additional file 2: Table S1. The distribution of Cyclin D1 staining results, angiolymphatic invasion, perineural invasion, family history, and Gleason score among $\mathrm{BPH}$ and $\mathrm{PC}$ patients.
Abbreviations

$\mathrm{BPH}$ : Benign prostatic hyperplasia; H\&E: Hematoxylin and Eosin; PC: Prostate cancer.

\section{Acknowledgements}

We would like to thank the staff of the Military Hospital and Soba teaching hospital, in Khartoum state-Sudan for their kind collaboration and assistance. And also great thanks to all participants contributed to this work.

\section{Authors' contributions}

ESA, LSE, RH, EES and NSM provided conceptual framework for the project, guidance for interpretation of the data, performed data analysis, NSM, EES, MAM, ETA and AM participated in the preparation of the samples. ETA, MEC, ESA, LSE, RH and AMME performed the cytological diagnosis. NSM, MSM, AM and AMME performed the statistical analysis and guidance for data interpretation. All authors read and approved the final manuscript.

\section{Funding}

Not applicable.

\section{Availability of data and materials}

The datasets used and/or analyzed during the current study are available from the corresponding author on reasonable request.

\section{Ethics approval and consent to participate}

The study was approved by the Faculty of Medical Laboratory Sciences Research Ethics Committee-University of Khartoum, Sudan. Informed consent was obtained from each participant prior to enrollment using writing and verbal informed consent in case of illiterate patients.

\section{Consent to publish}

Not applicable.

\section{Competing interests}

The authors declare that they have no competing interests.

\section{Author details}

${ }^{1}$ Mycetoma Research Center, University of Khartoum, Khartoum, Sudan.

2 Department of Cytology and Histopathology, Faculty of Medical Laboratory Sciences, University of Khartoum, Khartoum, Sudan. ${ }^{3}$ Nile University- School of Medicine, Khartoum, Sudan. ${ }^{4}$ Department of Histopathology and Cytology, Alfarrabi College for Science and Technology, Khartoum, Sudan. ${ }^{5}$ Faculty of Medicine, National University, Khartoum, Sudan. ${ }^{6}$ Department of Histopathology and Cytology, Faculty of Medical Laboratory Sciences, National University, Khartoum, Sudan. ${ }^{7}$ Department of Parasitology and Medical Entomology, Faculty of Medical Laboratory Sciences, Nile University, Khartoum, Sudan. ${ }^{8}$ Department of Bioinformatics and Biostatistics, National University Research Institute, National University, Khartoum, Sudan. ${ }^{9}$ Department of Neurology, Mayo Clinic, Jacksonville, FL, USA. ${ }^{10}$ Department of Radiology, Mayo Clinic, Jacksonville, FL, USA. ${ }^{11}$ Department of Internal Medicine, Faculty of Medicine, University of Khartoum, Khartoum, Sudan. ${ }^{12}$ Department of Parasitology and Medical Entomology, Faculty of Medicine, Sinnar University, Sinnar, Sudan. ${ }^{13}$ Molecular Biology Department, Alfarrabi College for sciences and Technology, Khartoum, Sudan. ${ }^{14}$ Department of Histopathology and Cytology, Faculty of Applied Medical Sciences, University of Bisha, Bisha, Kingdom of Saudi Arabia.

Received: 3 July 2019 Accepted: 14 June 2020

Published online: 17 June 2020

\section{References}

1. Bray F, Ferlay J, Soerjomataram I, Siegel RL, Torre LA, Jemal A. Global cancer statistics 2018: GLOBOCAN estimates of incidence and mortality worldwide for 36 cancers in 185 countries. CA Cancer J Clin. 2018;68(6):394-424.

2. Manna AK, Pathak S, Gayen P, Sarkar DK, Kundu AK. Study of immunohistochemistry in prostatic lesions with special reference to proliferation and invasiveness. Indian J Surg. 2011;73(2):101-6. 
3. Xu Y, Wang Y, Zhou R, Li H, Cheng H, Wang Z, Zhang J. The benign mimickers of prostatic acinar adenocarcinoma. Chin J Cancer Res. 2016;28(1):72

4. Ortiz AB, Garcia D, Vicente Y, Palka M, Bellas C, Martin P. Prognostic significance of cyclin D1 protein expression and gene amplification in invasive breast carcinoma. PLoS ONE. 2017;12(11):e0188068.

5. Li Y, Wei J, Xu C, Zhao Z, You T. Prognostic significance of cyclin D1 expression in colorectal cancer: a meta-analysis of observational studies. PLoS ONE. 2014;9(4):e94508.

6. Yang WI, Chung KY, Shin DH, Kim YB. Cyclin D1 protein expression in lung cancer. Yonsei Med J. 1996;37:142-50.

7. Keum J, Kong G, Yang S, Shin D, Park S, Lee J, Lee J. Cyclin D1 overexpression is an indicator of poor prognosis in resectable non-small cell lung cancer. Br J Cancer. 1999;81(1):127.

8. Pereira R, Ravinal R, Costa RS, Lima M, Tucci S, Muglia V, Dos Reis R, Silva GEB. Cyclin D1 expression in prostate carcinoma. Braz J Med Bio Res. 2014;47(6):515-21.

9. Saeed IE, Weng HY, Mohamed KH, Mohammed SI. Cancer incidence in Khartoum, Sudan: first results from the Cancer Registry, 2009-2010. Cancer Med. 2014;3(4):1075-84.

10. Saeed ME, Cao J, Fadul B, Kadioglu O, Khalid HE, Yassin Z, Mustafa SM, Saeed E, Efferth T. A five-year survey of cancer prevalence in Sudan. Anticancer Res. 2016;36(1):279-86.

11. Kulhánová I, Bray F, Fadhil I, Al-Zahrani AS, El-Basmy A, Anwar WA, AlOmari A, Shamseddine A, Znaor A, Soerjomataram I. Profile of cancer in the Eastern Mediterranean region: the need for action. Cancer Epidemiol. 2017:47:125-32

12. Gleason DF. Histologic grading of prostate cancer: a perspective. Hum Pathol. 1992;23(3):273-9.

13. Nakamura Y, Felizola SJ, Kurotaki Y, Fujishima F, McNamara KM, Suzuki T, Arai Y, Sasano H. Cyclin D1 (CCND1) expression is involved in estrogen receptor beta (ERß) in human prostate cancer. Prostate. 2013;73(6):590-5.

14. Aaltomaa S, Eskelinen M, Lipponen P. Expression of cyclin A and D proteins in prostate cancer and their relation to clinopathological variables and patient survival. Prostate. 1999;38(3):175-82.

15. Wong M, Bierman Y, Pettaway C, Kittles R, Mims M, Jones J, Ittmann M. : Comparative analysis of p 16 expression among African American and European American prostate cancer patients. Prostate. 2019;79(11):1274-83.

16. Wu X, Scott H, Carlsson SV, Sjoberg DD, Cerundolo L, Lilja H, Prevo R, Rieunier G, Macaulay V, Higgins GS. Increased EZH2 expression in prostate cancer is associated with metastatic recurrence following external beam radiotherapy. Prostate. 2019;79(10):1079-89.

17. Duijvesz D, Rodriguez-Blanco G, Hoogland AM, Verhoef El, Dekker LJ, Roobol MJ, van Leenders GJ, Luider TM, Jenster G. Differential tissue expression of extracellular vesicle-derived proteins in prostate cancer. Prostate. 2019;79(9):1032-42.

18. Krzyzanowska A, DonDoncow N, Marginean FE, Gaber A, Watson RW, Hellsten R, Bjartell A. Expression of tSTAT3, pSTAT3727, and pSTAT3 705 in the epithelial cells of hormone-naïve prostate cancer. Prostate. 2019;79(7):784-97.

19. Nie L, Pan X, Zhang M, Yin X, Gong J, Chen X, Xu M, Zhou Q, Chen N. The expression profile and heterogeneity analysis of ERG in 633 consecutive prostate cancers from a single center. Prostate. 2019;79(8):819-25.

20. Zukerberg LR, Yang W-I, Gadd M, Thor AD, Koerner FC, Schmidt EV, Arnold A. Cyclin D1 (PRAD1) protein expression in breast cancer: approximately one-third of infiltrating mammary carcinomas show overexpression of the cyclin D1 oncogene. Mod Pathol. 1995;8(5):560-7.

21. Naitoh H, Shibata J, Kawaguchi A, Kodama M, Hattori T. Overexpression and localization of cyclin D1 mRNA and antigen in esophageal cancer. Am J Pathol. 1995;146(5):1161.

22. Chen Y, Martinez LA, LaCava M, Coghlan L, Conti CJ. Increased cell growth and tumorigenicity in human prostate LNCaP cells by overexpression to cyclin D1. Oncogene. 1998;16(15):1913.

23. Hashimoto Y, Nakamura N, Kuze T, Abe M, Wakasa H. Intranuclear expression of cyclin D1 protein as a useful prognostic marker for mantle cell lymphoma. Fukushima J Med Sci. 1997;43(2):87-98.
24. Gansauge S, Gansauge F, Ramadani M, Stobbe H, Rau B, Harada N, Beger HG. Overexpression of cyclin D1 in human pancreatic carcinoma is associated with poor prognosis. Cancer Res. 1997;57(9):1634-7.

25. Shin K, Kong G, Kim W, Lee T, Woo Y, Lee J. Overexpression of cyclin D1 correlates with early recurrence in superficial bladder cancers. $\mathrm{Br} J$ Cancer 1997;75(12):1788

26. Gumbiner LM, Gumerlock PH, Mack PC, Chi SG, deVere White RW, Mohler $J \mathrm{~L}$, Pretlow TG, Tricoli JV. Overexpression of cyclin D1 is rare in human prostate carcinoma. Prostate. 1999;38(1):40-5.

27. Bahnassy AA, Zekri A-RN, El-Houssini S, El-Shehaby AM, Mahmoud MR, Abdallah S, El-Serafi M. Cyclin A and cyclin D1 as significant prognostic markers in colorectal cancer patients. BMC Gastroenterol. 2004;4(1):22.

28. Dunsmuir W, Gillett C, Meyer L, Young M, Corbishley C, Eeles R, Kirby R. Molecular markers for predicting prostate cancer stage and survival. BJU Int. 2000;86(7):869-78.

29. Ozbek E, Mizrak B, Ozbek M, Buyukberber S, Davarci M. CyclinD1 protooncogen expression in prostate cancer. Turk J Cancer. 2000;30(30):15-21.

30. Kallakury BV, Sheehan CE, Ambros RA, Fisher HA, Kaufman RP, Ross JS. The prognostic significance of p34cdc2 and cyclin D1 protein expression in prostate adenocarcinoma. Interdiscip Int J Am Cancer Soc. 1997:80(4):753-63.

31. Han EKH, Lim JT, Arber N, Rubin MA, Xing WQ, Weinstein IB. Cyclin D1 expression in human prostate carcinoma cell lines and primary tumors. Prostate. 1998:35(2):95-101.

32. Tsai H, Morais CL, Alshalalfa M, Tan H-L, Haddad Z, Hicks J, Gupta N, Epstein Jl, Netto GJ, Isaacs WB. Cyclin D1 loss distinguishes prostatic small-cell carcinoma from most prostatic adenocarcinomas. Clin Cancer Res. 2015:21(24):5619-29.

33. Drobnjak M, Osman I, Scher HI, Fazzari M, Cordon-Cardo C. Overexpression of cyclin D1 is associated with metastatic prostate cancer to bone. Clin Cancer Res. 2000;6(5):1891-5.

34. Fleischmann A, Rocha C, Saxer-Sekulic N, Zlobec I, Sauter G, Thalmann GN. High-level cytoplasmic cyclin D1 expression in lymph node metastases from prostate cancer independently predicts early biochemical failure and death in surgically treated patients. Histopathology. 2011;58(5):781-9.

35. He Y, Franco OE, Jiang M, Williams K, Love HD, Coleman IM, Nelson PS, Hayward SW. Tissue-specific consequences of cyclin D1 overexpression in prostate cancer progression. Cancer Res. 2007;67(17):8188-97.

36. Ding G, Liu J, Feng C, Jiang H, Xu J, Ding Q. Slug regulates Cyclin D1 expression by ubiquitin-proteasome pathway in prostate cancer cells. Panminerva Med. 2012;54(3):219-23.

37. Koontz BF, Tsivian M, Mouraviev V, Sun L, Vujaskovic Z, Moul J, Lee WR. Impact of primary Gleason grade on risk stratification for Gleason score 7 prostate cancers. Int J Radiation Oncol Biol Phys. 2012;82(1):200-3.

38. Lughezzani G, Gallina A, Larcher A, Briganti A, Capitanio U, Suardi N, Lista G, Abrate A, Sangalli MN, Buffi N. Radical prostatectomy represents an effective treatment in patients with specimen-confined high pathological Gleason score prostate cancer. BJU Int. 2013;111(5):723-30.

39. Wilt TJ, Abrahamsson P-A, Crawford ED, Lucia MS, Sakr WA, Schalken J. Prostate cancer: epidemiology and screening. Rev Urol. 2003;5(Suppl 6):S3.

40. Cookson MS, Fleshner NE, Soloway SM, Fair WR. Correlation between Gleason score of needle biopsy and radical prostatectomy specimen: accuracy and clinical implications. J Urol. 1997;157(2):559-62.

41. Kulkarni JN, Valsangkar RS, Jadhav YR, Singh DP. Impact of Gleason pattern up gradation after radical prostatectomy for carcinoma prostate patients with low biopsy score ( $\leq 6)$. J Cancer Res Therap. 2011;7(4):459.

\section{Publisher's Note}

Springer Nature remains neutral with regard to jurisdictional claims in published maps and institutional affiliations. 